\title{
Reliability of Power System Integrated with Wind Generation Considering Carbon Tax
}

\author{
Xinwen Ni, Kwok Lun Lo \\ Power System Research Group, Department of Electronic and Electrical Engineering, Glasgow, UK \\ Email: xinwen.ni@strath.ac.uk, k.lo@strath.ac.uk
}

How to cite this paper: Ni, X.W. and Lo, K.L. (2016) Reliability of Power System Integrated with Wind Generation Considering Carbon Tax. World Journal of Engineering and Technology, 4, 50-57.

http://dx.doi.org/10.4236/wjet.2016.43D007

Received: July 13, 2016

Accepted: October 13, 2016

Published: October 20, 2016

\begin{abstract}
This paper proposes a method to evaluate the reliability of power system with different capacities of wind power while considering carbon tax. The proposed method is a hybrid approach which combines Frequency and Duration (F\&D) method and Monte Carlo Simulation (MCS) method. MCS method is used to achieve a model to simulate the random status of power system. Also, the proposed method is applied on the IEEE 14-bus test system to investigate the effects of integrating different capacities of wind energy to the reliability of power system with considering carbon tax.
\end{abstract}

\section{Keywords}

Wind Power Integration, Power System Reliability, Carbon Tax

\section{Introduction}

Renewable energy replacing traditional energy sources is an inevitable fact as more and more people have come to realize that the amount of easily obtainable fossil fuel is limited and keeps decreasing as well as the severe influences of by product of burning fossil fuels. Many countries had announced plans to replace traditional energy sources partially or entirely with renewable energy. According to UK government, $15 \%$ of the total energy demand will be generated using renewable sources by 2020 [1]. However, due to the intermittent and inconsistent nature of the wind, implementation of wind power into the current power grid could severely affect its performance. Moreover, integration of wind energy requires a significant amount of capital investment for network reinforcement and ancillary services. Approximately $75 \%$ of the total cost of energy for a wind turbine is related to upfront costs such as the expense of the turbine, foundation, electrical equipment, grid-connection and so on [3]. Also, implementation 
of wind energy helps to reduce the amount of $\mathrm{CO}_{2}$ emission which leads to less expense of carbon tax.

The primary function of the power system is to provide electrical power to its customers as economically as possible with an acceptable degree of quality [2]. In other words, providing cheap electricity to consumers while keeping a certain level of reliability.

Reliability has always been and still is one of the most important factors when operating and maintaining a power system [8]. System reliability evaluation methods can be categorized into two groups, deterministic and probabilistic methods. Probabilistic methods are more widely used as it reflects the operating process of the power system in a better way. There are two aspects of probabilistic methods, analytical methods and Monte Carlo Simulation (MCS) methods. Analytical methods like Markov Chain Method and Frequency and Duration (F \& D) Method utilize mathematical models to represent power system and calculate different reliability indices through equations. Analytical methods can provide accurate results of power system reliability directly once given input data. The process can be very quick as long as the test system is simple. However, when it comes to large systems that contain lots of generating units and loads with various working status, the computation speed can slow down significantly, and the memory required to process and store data also increases considerably. MCS methods, on the other hand, represent the entire system with software modules and simulate the operating process of the power system while considering random behaviors of all participants. MCS method is based on repeating random sampling simulations to obtain results that as close to the real one as possible. Thus it can reflect the intermittent nature of wind power. This paper proposes a new method that combines MCS with F\&D while taking carbon tax into consideration. And this method is tested using modified IEEE 14-bus system in MATPOWER [4], a package developed within MATLAB.

\section{Simulation Process}

Loss of Load Expectation (LOLE) is one of the most widely used probabilistic methods in power system reliability analysis. It is defined as the average hours/days per year that load demand exceeds power supply. F\&D method is an extension of LOLE as it also provides information about the expected frequency and duration of inadequacy. However, it cannot reflect the severeness of each encounter by showing the amount of power shortage. Loss of Energy Expectation measures the expected amount of electricity not to be met by generation in one year. Combining these two approaches together will give a more accurate method that provides all of the information. Nevertheless, the computation burden increases significantly when taking wind power into account due to the characteristics of wind energy. On the contrary, MCS method can be applied to simulate the random behaviors of the system without considering the generating unit's output nature [5]. 


\subsection{Test System}

The test system used in this paper is modified based on the IEEE 14-bus test system as shown in Figure 1. This test system contains five generators and 11 loads. The maximum power output is $772.4 \mathrm{MW}$ and the total amount of electricity demand is 259 MW. And a wind farm is connected to bus 3 . The system is tested mainly in two scenarios, with and without considering line constraints.

\subsection{Wind Power Generation Model}

Wind power employed in this paper is generated using Wei bull distribution function. By setting the scale factor $\alpha$ to 7 and shape factor $\beta$ to 2 , wind speed can be produced as Figure 2 shows. And for the sake of simplicity, only partial wind speed data is presented in the illustration. Figure 3 illustrates the sorted wind speed which fits the Wei

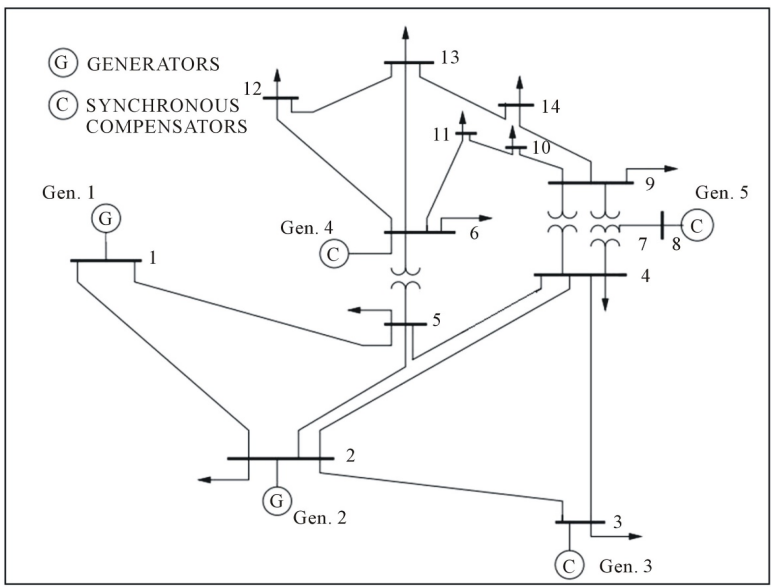

Figure 1. IEEE 14-bus test system [6].

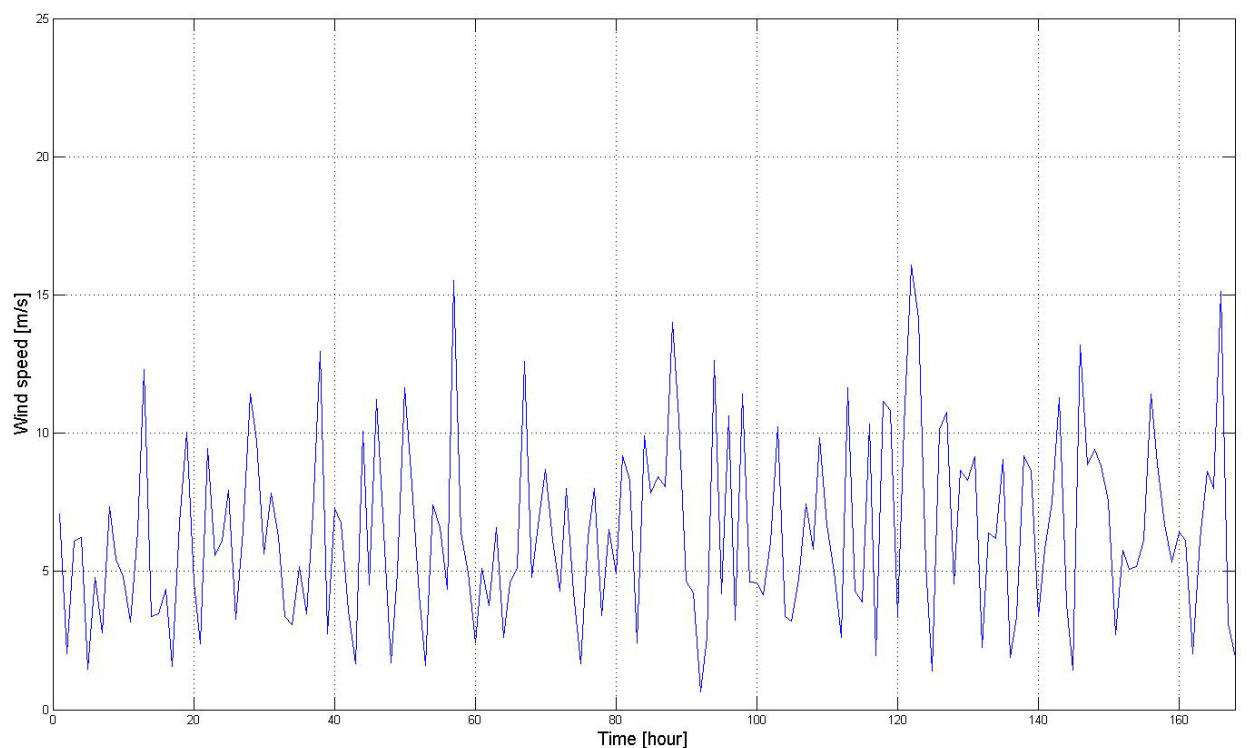

Figure 2. Generated wind speed. 


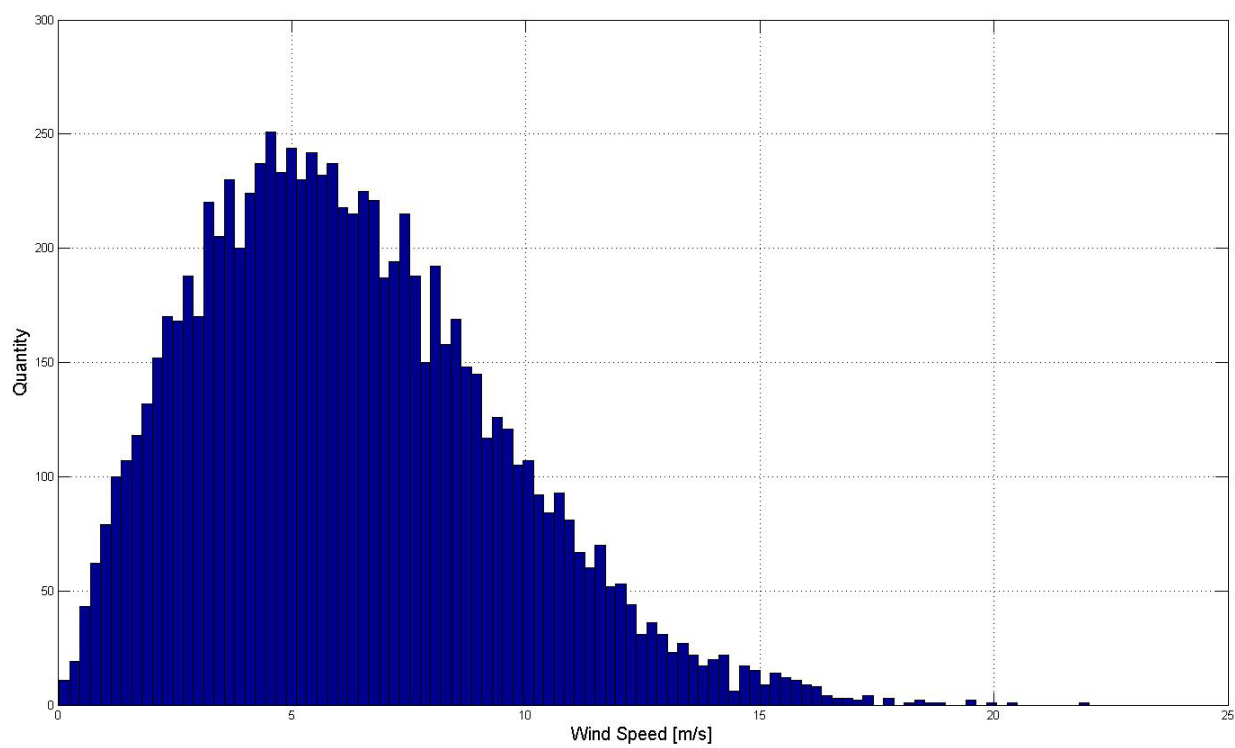

Figure 3. Sorted wind speed.

bull distribution roughly. Then wind power output can be calculated using Equation (1). In this paper, cut-in speed is set to $4 \mathrm{~m} / \mathrm{s}$, rated speed is $10 \mathrm{~m} / \mathrm{s}$, cut-out speed is 25 $\mathrm{m} / \mathrm{s}$ and rated power is $30 \mathrm{MW}$. And the price of wind energy is set to zero since it is considered as a must-taken source of energy.

$$
P_{w}=\left\{\begin{array}{cc}
0 & w s<V_{c i} \\
\left(A+B * w s+C * w s^{2}\right) & V_{c i} \leq w s<V_{r} \\
P_{w r} & V_{r} \leq w s<V_{c o} \\
0 & w s \geq V_{c o}
\end{array}\right.
$$

where:

ws is the wind speed

$\mathrm{V}_{\mathrm{ci}}$ is the cut-in speed of wind turbine

$V_{r}$ is the rated speed of wind turbine

$\mathrm{V}_{\text {со }}$ is the cut-out speed of wind turbine

$P_{w r}$ is the rated power output of the wind turbine

$\mathrm{A}, \mathrm{B}$ and $\mathrm{C}$ are constants calculated using cut-in and rated speed.

\section{Case Analysis}

A few cases are carried out to study the effect of wind power integration on power system while considering the cost of carbon tax. Assuming that [7] $6.89551 \times 10^{-4}$ metric tons of $\mathrm{CO}_{2}$ is generated to produce one kWh electricity by burning coal. And the carbon tax is 0.028 dollar per kWh.

\subsection{Without Considering Line Constraints}

In this section, the system is tested when connected with $5 \%$ and $10 \%$ wind power without taking transmission line constraints into account. Figure 4 and Figure 5 shows 


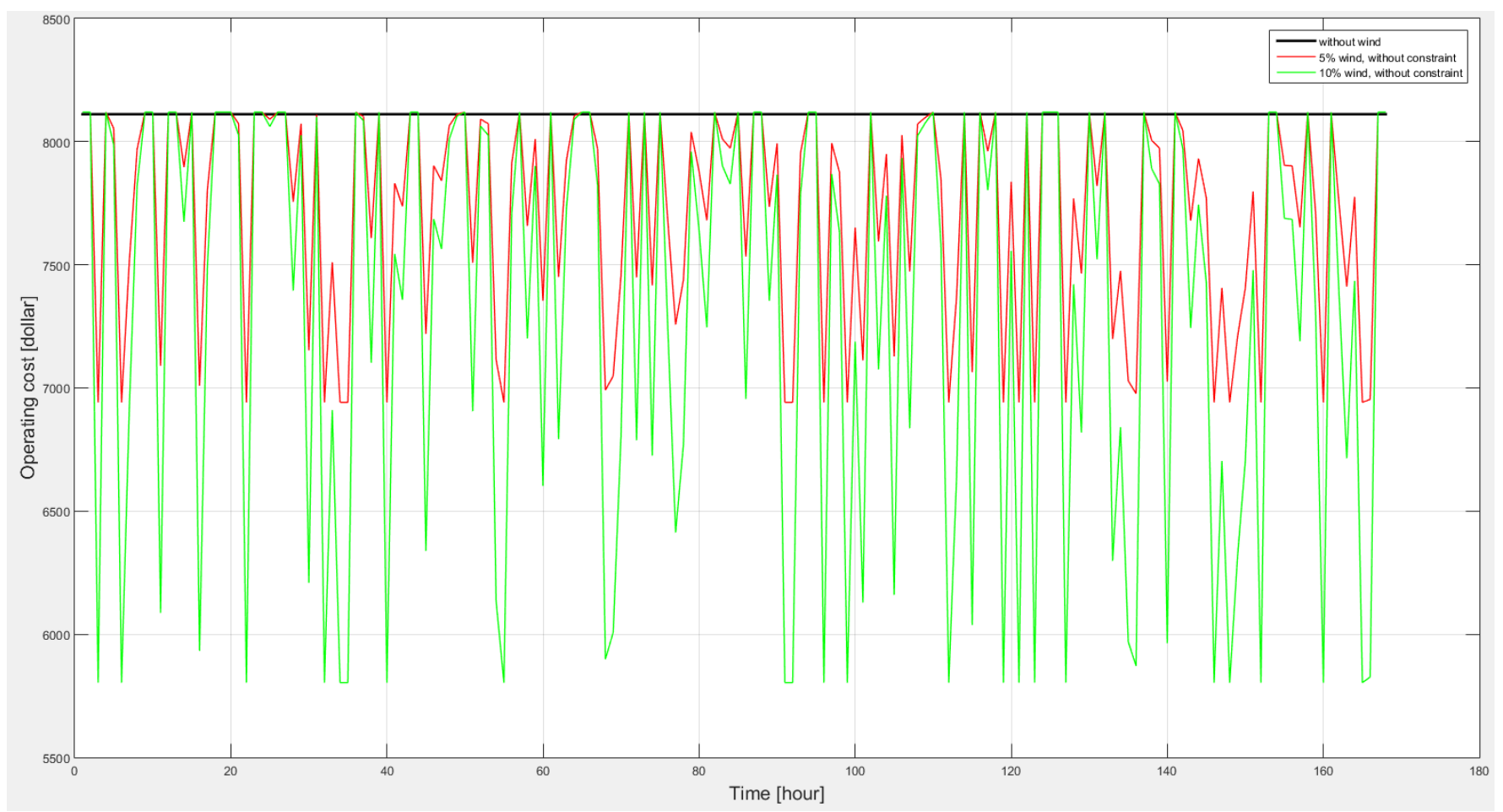

Figure 4. System operating cost, $5 \%$ and $10 \%$ wind power, no constratints.

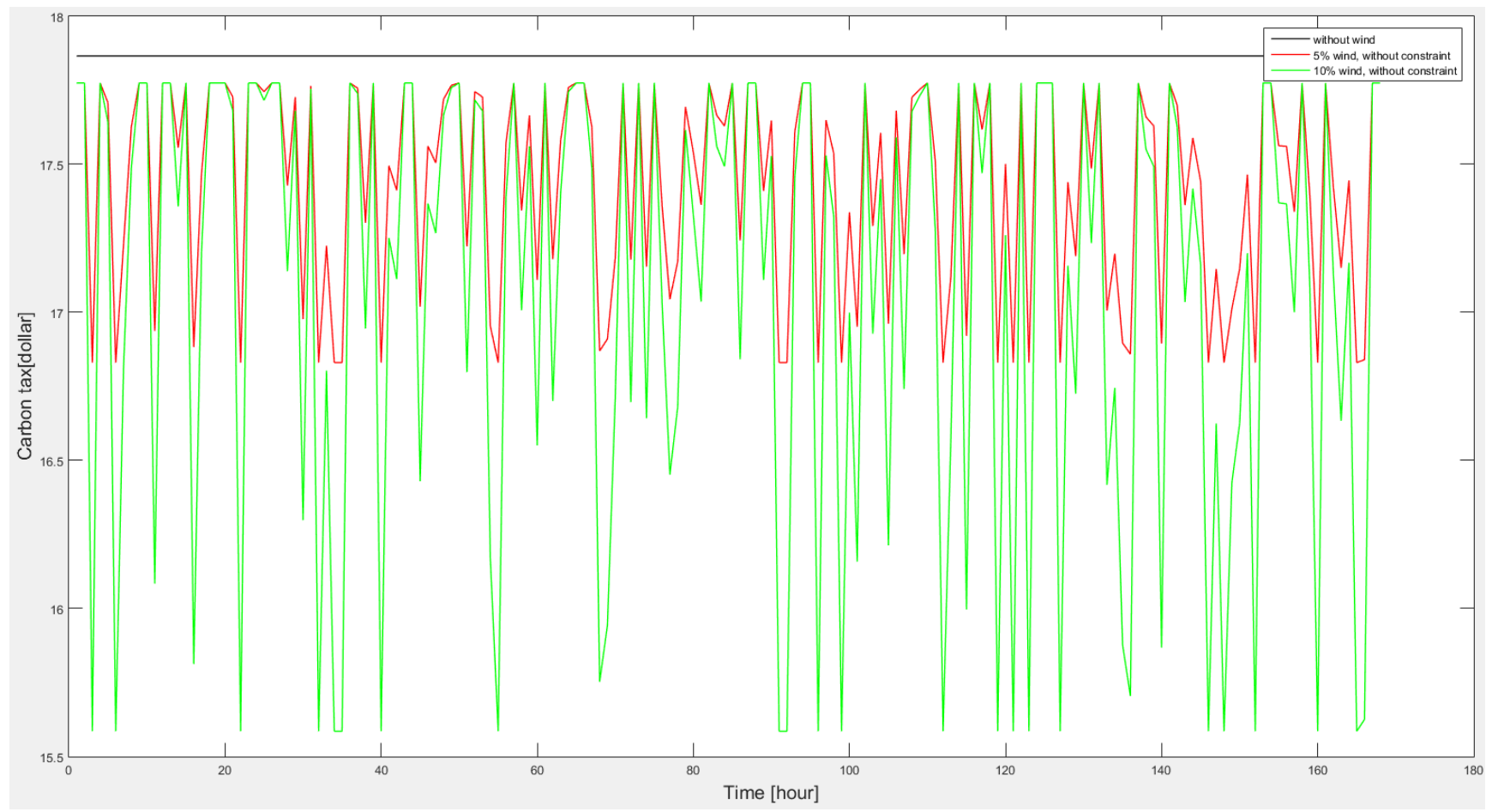

Figure 5. Carbon cost of the test system, 5\% and 10\% wind power, no constratints.

the system operating cost and carbon cost respectively. The black line indicates the base case without connecting to wind farms while the red and green broken line represents 
system connected to $30 \mathrm{MW}$ and $60 \mathrm{MW}$ wind farm. Figure 4 and Figure 5 looks very similar to operating cost and carbon cost are both calculated based on the total power generation. Figure 4 shows that after connecting wind farm to bus, the operating cost is reduced significantly. And the system connected with $60 \mathrm{MW}$ wind power has larger reduction than $30 \mathrm{MW}$. The maxim reduction of operating cost of $30 \mathrm{MW}$ and $60 \mathrm{MW}$ penetration level are $1178 \$ / \mathrm{hr}$ and $2316 \$ / \mathrm{hr}$ respectively. Figure 5 indicates that the system has larger wind power capacity tend to have less expense of carbon cost. However, in Figure 4, there are some points that the operating costs are higher than before. This happens when the wind output is low and cannot provide enough electric power to consumers and generators with much greater price have to be brought online. Table 1 showcases one extreme situation where the wind output is zero.

\subsection{Considering Line Constraints}

In this case, a $30 \mathrm{MW}$ maxim limit is introduced to all of the transmission lines. The blue and red line indicate $5 \%$ and $10 \%$ wind power penetration level respectively. Figure 6 and Figure 7 have very similar look comparing to Figure 4 and Figure 5. The operating cost is reduced and the system with higher wind power penetration level tend to have a larger price drop. As Table 2 shows, when transmission line limit is considered, system operating cost has smaller decrease comparing to it without taking constraint into account. This happens when wind farm has abundant output. After meeting the local demand, the extra electricity is prevented being distributed to other buses by

Table 1. Bus data, unconstratined, $30 \mathrm{MW}$ wind.

\begin{tabular}{|c|c|c|c|}
\hline Bus No. & Generation (MW) & Load (MW) & LMP (\$/MWh) \\
\hline 1 & 195.44 & - & 36.819 \\
\hline 2 & 36.37 & 21.70 & 38.382 \\
\hline 3 & 0 & 24.20 & 39.818 \\
\hline 4 & - & 67.80 & 40.574 \\
\hline 5 & - & 17.60 & 40.085 \\
\hline 6 & 10.33 & 11.20 & 40.206 \\
\hline 7 & - & - & 40.546 \\
\hline 8 & 26.83 & - & 40.537 \\
\hline 9 & - & 29.50 & 40.550 \\
\hline 10 & - & 19.00 & 41.048 \\
\hline 11 & - & 13.50 & 41.106 \\
\hline 12 & - & 16.10 & 41.619 \\
\hline 13 & - & 13.50 & 41.330 \\
\hline 14 & - & 24.90 & 42.392 \\
\hline Operating cost & $8119.82(\$ / \mathrm{hr})$ & Carbon tax & $17.7750 \$ / \mathrm{hr}$ \\
\hline LOLE & - & LOEE & - \\
\hline
\end{tabular}




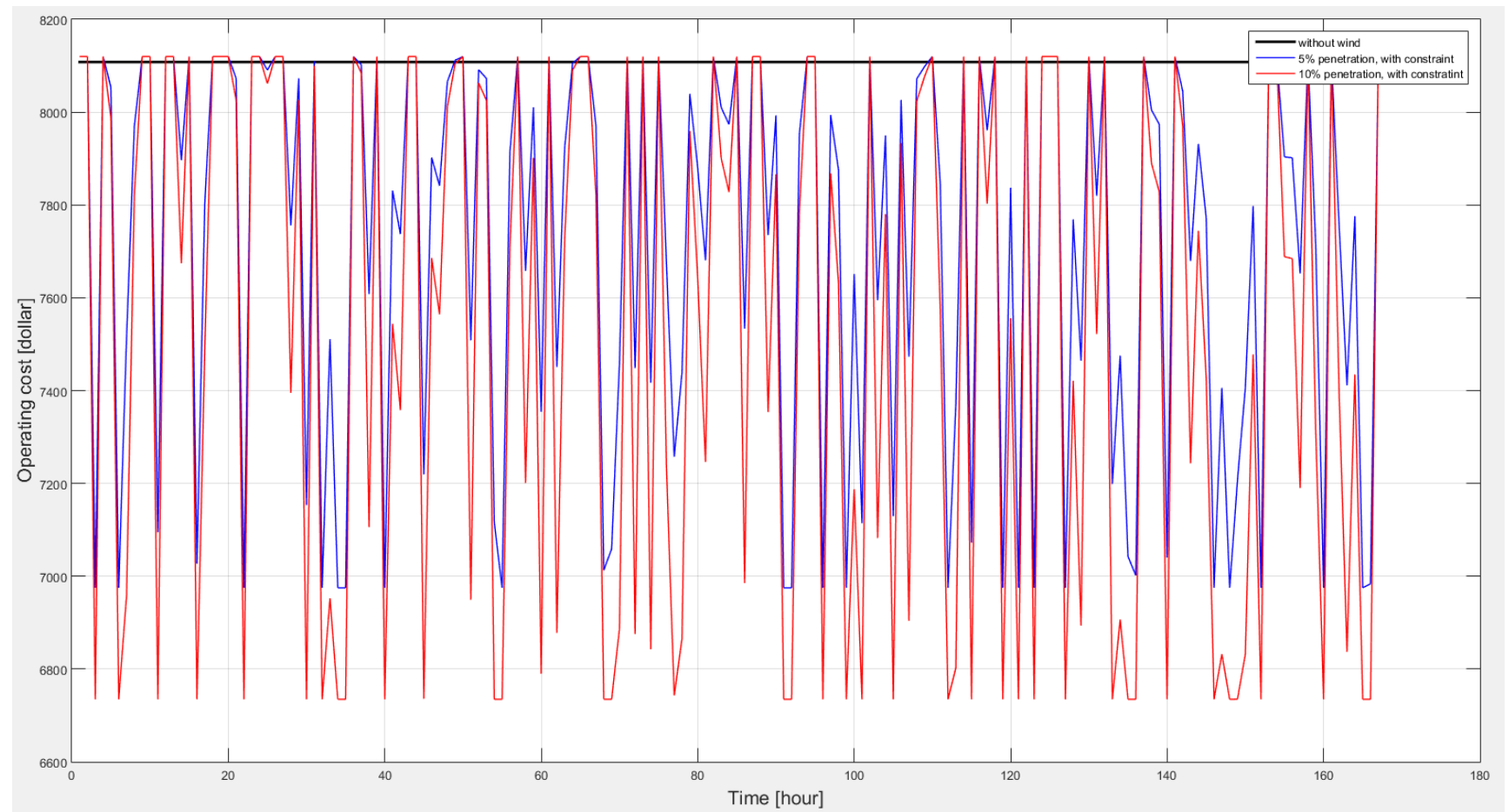

Figure 6. System operating cost connecting $5 \%$ and $10 \%$ wind power, considering constratints.

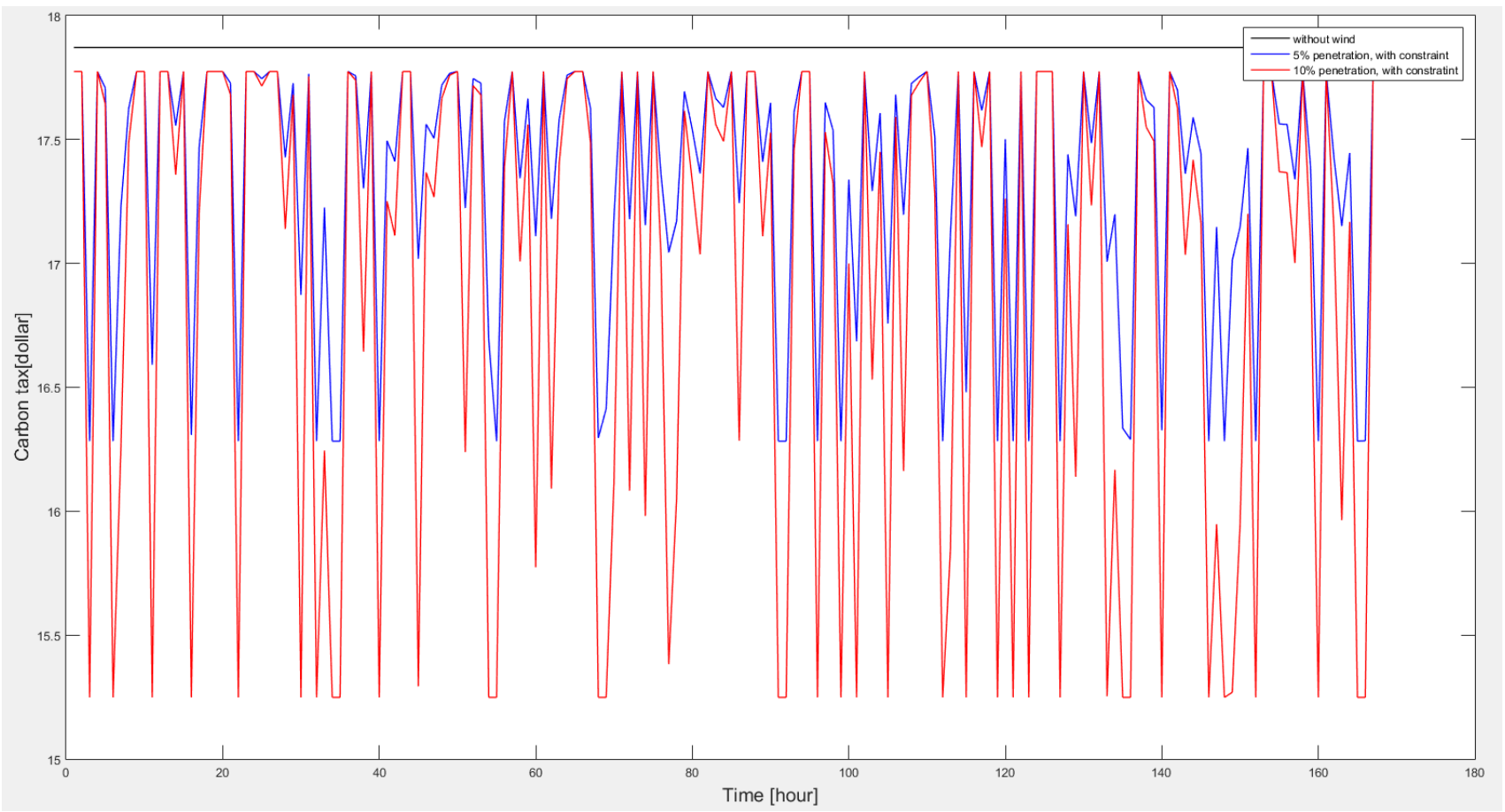

Figure 7. System operating cost connecting $5 \%$ and $10 \%$ wind power, considering constratints.

the transmission line limit. The LOLE and LOEE when $30 \mathrm{MW}$ of wind power connected is 4.2 hours per week and $15.39 \mathrm{MW}$ respectively. When $60 \mathrm{MW}$ of wind power is integrated into the system, the indices increases to 5.56 and 18.11 . 
Table 2. Camparision of operating cost and carbon cost.

\begin{tabular}{ccccc}
\hline & $\begin{array}{c}\text { Max } \\
\text { operating } \\
\text { cost }\end{array}$ & $\begin{array}{c}\text { Min } \\
\text { operating } \\
\text { Cost }\end{array}$ & $\begin{array}{c}\text { Max } \\
\text { carbon } \\
\text { cost }\end{array}$ & $\begin{array}{c}\text { Min } \\
\text { carbon } \\
\text { cost }\end{array}$ \\
\hline Base case & 8108 & 8108 & 17.87 & 17.87 \\
Unconstrained 5\% wind power & 8119 & 6941 & 17.77 & 16.83 \\
Unconstrained 10\% wind power & 8119 & 5803 & 17.77 & 15.58 \\
Constrained 5\% wind power & 8119 & 6975 & 17.77 & 16.28 \\
Constrained 10\% wind power & 8119 & 6934 & 17.77 & 15.24 \\
\hline
\end{tabular}

\section{Conclusion}

This paper presents a way to evaluate system reliability while considering carbon tax. It shows that wind power integration help to reduce the operating cost and carbon cost by cutting the emission of $\mathrm{CO}_{2}$ though it requires a large amount of capital investment. Power system reliability, on the other hand, is also affected by integrating wind power.

\section{References}

[1] Department of Energy and Climate Change (2011) UK Renewable Energy Road Map. https://www.gov.uk/government/uploads/system/uploads/attachment_data/file/48128/2167 -uk-renewable-energy-roadmap.pdf

[2] Li, W.Y. and Billinton, R. Reliability Assessment of Electric Power Systems Using Monte Carlo Methods.

[3] The European Wind Energy Association. The Economics of Wind Energy. http://www.ewea.org/fileadmin/files/library/publications/reports/Economics_of_Wind_Ene rgy.pdf

[4] Zimmerman, R.D., Murillo-Sánchez, C.E. and Thomas, R.J. (2011) MATPOWER: SteadyState Operations, Planning and Analysis Tools for Power Systems Research and Education. IEEE Transactions on Power Systems, 26, 12-19.

[5] Shi, S. and Lo, K.L. Reliability Assessment of Power System Considering the Impact of Wind Energy.

[6] https://www.ee.washington.edu/resear/pstca/pf14/pg_tcal14bus.thm

[7] US Department of Energy, Energy Information Administration. Fuel and Energy Source Codes and Emission Coefficient.

[8] Nikzad, M., Shams, S., Farahani, S. and Tabar, M.B. (2012) Calculation of Generation System Reliability Index: Loss of Load Expectation. Life Science Journal, 9. 
Submit or recommend next manuscript to SCIRP and we will provide best service for you:

Accepting pre-submission inquiries through Email, Facebook, LinkedIn, Twitter, etc. A wide selection of journals (inclusive of 9 subjects, more than 200 journals)

Providing 24-hour high-quality service

User-friendly online submission system

Fair and swift peer-review system

Efficient typesetting and proofreading procedure

Display of the result of downloads and visits, as well as the number of cited articles

Maximum dissemination of your research work

Submit your manuscript at: http://papersubmission.scirp.org/

Orcontactwjet@scirp.org 